\title{
Endoscopic submucosal dissection for gastric neoplasm in patients with co-morbidities categorized according to the ASA Physical Status Classification
}

\author{
Mariko Man-i · Yoshinori Morita · Tsuyoshi Fujita · James E. East • \\ Shinwa Tanaka - Chika Wakahara • Masaru Yoshida - Takanobu Hayakumo • \\ Hiromu Kutsumi · Hideto Inokuchi · Takashi Toyonaga • Takeshi Azuma
}

Received: 8 October 2011 / Accepted: 26 January 2012/Published online: 2 March 2012

(c) The International Gastric Cancer Association and The Japanese Gastric Cancer Association 2012

\begin{abstract}
Background Endoscopic submucosal dissection (ESD) has come to be widely performed for reduced invasiveness; however, its safety in patients with co-morbidities is not fully examined. We aimed to evaluate the safety and efficacy of gastric ESD with co-morbidities categorized according to ASA Physical Status Classification.

Methods Two hundred and forty patients of ASA 1 (no co-morbidities), 268 of ASA 2 (mild), and 19 of ASA 3 (severe) were treated by ESD for gastric neoplasms. We retrospectively compared clinicopathological features and treatment results of these three groups.

Results Cases (by percent) treated with anticoagulant/ platelet agents were more common in the higher ASA grades (ASA 1, 5.8\%; ASA 2, 29.1\%; ASA 3, 31.6\%; $P<0.0001)$. There were no significant differences in case numbers treated under guideline criteria, curative resection (ASA 1, 79.6\%; ASA 2, 79.9\%; ASA 3, 78.9\%), or complications related to the ESD procedure (e.g., postoperative
\end{abstract}

M. Man-i · Y. Morita · T. Fujita - S. Tanaka · C. Wakahara ·

M. Yoshida - T. Hayakumo - H. Kutsumi - T. Azuma

Department of Gastroenterology, Kobe University, Kobe, Japan

M. Man-i $(\square) \cdot$ T. Toyonaga

Department of Endoscopy, Kobe University Hospital,

7-5-1 Kusunoki-cho, Chuo-ku, Kobe 650-0017, Japan

e-mail: mariko-m@bc5.so-net.ne.jp

J. E. East

Translational Gastroenterology Unit, John Radcliffe Hospital,

Oxford, UK

H. Inokuchi

Department of Gastroenterology, Hyogo Cancer Center,

Akashi, Japan bleeding, perforation, thermal injury). By a patient risk prediction model on surgery, i.e., P-POSSUM, morbidity was halved, and no patients died compared to a predicted death rate of $0.5-2 \%$; however, total and complications unrelated to ESD procedure (e.g., aspiration pneumonia, ischemic heat attack) were more common in higher ASA grades (ASA 1, ASA 2, ASA 3: 15.4, 23.9, 26.3\%, respectively, $P=0.014 ; 0.4,7.1,0 \%$, respectively, $P=0.00087$ ). Deviation rates from clinical pathway were more frequent and hospital stay (days) longer in higher ASA grades (ASA 1, ASA 2, ASA 3: 11.3, 17.9, $26.3 \%$, respectively, $P=0.014 ; 8,8,9 \%$, respectively, $P=0.0053$ ).

Conclusions ESD is an efficient treatment for gastric neoplasms with co-morbidities. However, additional caution is required because co-morbidity is a risk factor for both total complications and complications unrelated to the ESD procedure, and may cause deviations in the clinical course and prolonged hospital stay.

Keywords Stomach neoplasms - Endoscopic submucosal dissection (ESD) · Comorbidity · Complication · The American Society of Anesthesiologists (ASA) Physical Status Classification

$\begin{array}{ll}\text { Abbreviations } & \\ \text { ESD } & \text { Endoscopic submucosal dissection } \\ \text { EMR } & \text { Endoscopic mucosal resection } \\ \text { Upper } & \text { Upper third of the body } \\ \text { Middle } & \text { Middle third of the body } \\ \text { Lower } & \text { Lower third of the body } \\ \text { m-cancer } & \text { Intramucosal cancer } \\ \text { sm1-cancer } & \text { Minimally invasive submucosal cancer, } \\ & \text { invasion depth }<500 \mu \mathrm{m} \text { from the } \\ & \text { muscularis mucosa }\end{array}$


sm2-cancer

Invasive submucosal cancer, invasion depth $\geq 500 \mu \mathrm{m}$ from the muscularis mucosa

tub1

Tubular adenocarcinoma, well-differentiated type

tub2

pap

undiff

Thermal injury differentiated type

Papillary adenocarcinoma

Undifferentiated adenocarcinoma

Thermal injury caused by preventive coagulation

\section{Introduction}

Early-stage gastrointestinal neoplasms have been detected more often recently as a result of improvements in endoscopic examinations for patients with co-morbidities. In addition, a new endoscopic treatment, endoscopic submucosal dissection (ESD), has become widely accepted because it enables the en bloc resection of tumors and is considered to be less invasive than conventional surgical treatment. This curative but less radical treatment is desirable for patients with co-morbidities. However, ESD is relatively difficult to perform compared with conventional endoscopic mucosal resection (EMR) because it requires a longer procedure time and is associated with a higher incidence of complications [1, 2]. In addition, ESD requires deep conscious sedation. Appropriate perioperative risk assessment is thus necessary for safe ESD.

The American Society of Anesthesiologists (ASA) Physical Status Classification was developed as a means of defining preoperative risk, and a correlation between ASA classification and perioperative mortality has been reported $[3,4]$. In this study, we retrospectively evaluated the efficacy and safety of ESD for gastric neoplasms in patients with co-morbidities according to their ASA Physical Status Classification.

\section{Materials and methods}

\section{Patients}

Of a total of 770 gastric cancer lesions treated by ESD at Kobe University Hospital between November 2001 and July 2010, 527 early gastric cancer lesions that were treated between March 2007 and July 2010, after the introduction of the clinical pathway, were analyzed retrospectively. ASA Physical Status Classification was recorded for all patients: class 1 , healthy patients (no organic, physiological, psychiatric, or biochemical disturbances); class 2, mild systemic disease: no functional limitations (such as

cerebral vessel disease, respiratory disease, ischemic heart disease, arrhythmia, chronic liver disease, chronic renal dysfunction, hypertension, or diabetes mellitus); or class 3, severe systemic disease: definite functional limitation (such as diabetes with associated vascular complications, poorly controlled hypertension, a history of myocardial infarction, or emphysema). No patients were categorized as ASA class 4 or 5 because these high-risk patients are contraindicated for treatment under conscious sedation [5]. Patients who had undergone other endoscopic therapies such as argon plasma coagulation (APC) before ESD were excluded from this study. To assess the influence of co-morbidities on the outcome of ESD, we divided the patients into three groups: ASA 1 group $(n=240)$, ASA 2 group $(n=268)$, and ASA 3 group ( $n=19$ ), according to their ASA classification. All patients provided written informed consent before undergoing treatment. Follow-up endoscopic examinations were conducted to check for recurrence every 6 months in the first year after ESD and every 12 months thereafter.

\section{Criteria}

The indications for ESD were determined according to the patients' endoscopic characteristics and the histological findings of biopsy specimens. Endoscopic ultrasonography was also carried out when a lesion was strongly suspected of submucosal invasion. According to the guidelines of the Japanese Gastric Cancer Association (JGCA), intramucosal cancer without ulceration, of the differentiated type, and $\leq 2 \mathrm{~cm}$ in diameter was included under the guideline criteria for ESD, and the following lesions were categorized under the extended criteria:

1. Intramucosal cancer without ulceration, differentiated type, $>2 \mathrm{~cm}$ in diameter

2. Intramucosal cancer with ulceration, differentiated type, $\leq 3 \mathrm{~cm}$ in diameter.

\section{Complications}

In this study, we defined "complication" as Grade 3/4 of "toxicity criteria" [6]. Total complications were then divided into complications related to the ESD procedure and complications unrelated to the ESD procedure, as follows.

\section{Complications related to the ESD procedure}

Postoperative bleeding, perforation, and thermal injury caused by preventive coagulation were defined as suffering from complications related to ESD procedure. Postoperative bleeding was confirmed when hemostatic treatment by endoscopic management or blood transfusion was required within 2 weeks of the ESD procedure. Perforation was 
confirmed when the omentum or the abdominal cavity was visible during endoscopic treatment or when free air was recognized on radiography after the treatment. Transmural thermal injury resulted from serosal inflammation, which was caused by coagulation [7], and manifested as localized abdominal pain, leukocytosis, and occasionally fever.

\section{Complications unrelated to the ESD procedure}

Other complications such as aspiration pneumonia, arrhythmia, ischemic heat attack, and delirium were defined as complications unrelated to the ESD procedure.

Gastric ESD methods

\section{Clinical pathway (Table 1)}

Patients were admitted to our hospital 1 day before the ESD procedure. Tests of respiratory function, electrocardiograms, erect chest and abdominal X-rays, and blood tests were used to define the perioperative risk. All patients were given oral proton pump inhibitors (PPI) (sodium rabeprazole $20 \mathrm{mg}$ ) on the day of admission.

After the ESD procedure, all patients received intravenous PPI (omeprazole) $40 \mathrm{mg}$ and antibiotics (cefotiam hydrochloride) $2 \mathrm{~g}$ for 3 days, followed by 8 weeks of oral PPI (sodium rabeprazole) $20 \mathrm{mg}$. On the first postoperative day, a clinical examination and erect chest and abdominal $\mathrm{X}$-rays were performed to exclude delayed perforation. After the absence of perforation was confirmed, the first follow-up endoscopic examination was performed to exclude postoperative bleeding. In cases in which a small amount of bleeding or visible vessels were observed, preventive coagulation was performed. Blood tests were also performed on the first postoperative day. After having ruled out perforation and postoperative bleeding, oral intake was started. The patients were discharged from hospital when they could tolerate a regular diet, usually on the sixth postoperative day. However, postoperative bleeding was treated by blood transfusion when the patient's hemoglobin level decreased by $4 \mathrm{~g} / \mathrm{dl}$, and perforation was treated by endoscopic clipping, with nasogastric tube. Oral intake was postponed until the second or third postoperative day, and the administration of intravenous antibiotics was extended in cases involving complications. These cases are defined as deviation from the clinical pathway.

\section{ESD technique}

Endoscopic submucosal dissection was carried out with an insulated-tip (IT) knife (KD-610L KD-611L; Olympus, Tokyo, Japan) [2], IT knife 2 (KD-611L; Olympus) [8], or a Flush knife (DK-2618JN; FTS, Tokyo, Japan) [9, 10], through a conventional single-channel endoscope (GIFQ240, Q260, Q260J; Olympus). A transparent hood (D-201-10704; Olympus) was mounted on the tip of the endoscope to maintain a clear operative field. For marking, we used APC or the tip of the Flush knife in forced coagulation mode in combination with a high-frequency electrosurgical generator (VIO 300D; ERBE Elektromedizin, Tubingen, Germany). For local injection, saline mixed with epinephrine $(0.025 \% \mathrm{mg} / \mathrm{ml})$ was injected into the submucosal layer using a 25 -gauge endoscopic needle (Top Corporation, Tokyo, Japan), and sodium hyaluronate (MucoUp; Johnson \& Johnson, Tokyo, Japan) was added when the resultant elevation of the submucosa was insufficient. For mucosal incision, the Flush knife or IT knife was used to make an incision along the circumference of the lesion; then, the submucosal layer was dissected with the Flush knife in forced coagulation mode or with the IT knife in swift coagulation mode. When bleeding occurred, attempts were made to achieve hemostasis using the knife itself; first using the Flush knife (forced coagulation mode; effect 3, $45 \mathrm{~W}$ ), and then if this was unsuccessful after two or three attempts, Radial Jaw 3 hot biopsy forceps (REF1550; Boston Scientific) were used (soft coagulation mode; effect 6,100 W) $[11,12]$. After the resection, preventive coagulation of the visible vessels was performed in the resected area. The procedure time was measured from the beginning of the submucosal injection to completion of the resection.

\section{Sedation}

Midazolam was used for conscious sedation, and flunitrazepam was added if the initial sedation was insufficient. Haloperidol was used when the patient was delirious. In cases involving co-morbidities such as renal and liver dysfunction, the sedative doses were chosen carefully. Butorphanol was used for pain control throughout the procedure. Scopolamine was given as an antispasmodic to all patients who did not have contraindications. A depressor, nicardipine, was given to the patients with high systolic blood pressure (above $160 \mathrm{mmHg}$ ), and an infusion solution was loaded; an antihypotensive, effortil, was administered for those with low systolic blood pressure (below $80 \mathrm{mmHg}$ ). Oxygen was administered through the nasal cannula to those who displayed low peripheral oxygen saturation $\left(\mathrm{SpO}_{2}\right.$, below 95\%). Vital signs were monitored by electrocardiography, a sphygmomanometer, and a pulse oximeter.

Histological assessment

The resected specimens were fixed in formalin, sliced into 2-mm sections, and assessed microscopically with regard to the depth of invasion, histological type, lymphovascular invasion, and the lateral and vertical resection margins, 





according to the JGCA gastric cancer treatment guidelines $[13,14]$.

Definition of en bloc resection and curative resection

En bloc resection was defined as a one-piece resection including tumor-free margins.

Specimens meeting the foregoing criteria as well as the criteria described below were considered to represent "en bloc R0 curative resection" with little risk of lymph node metastasis:

1. Intramucosal cancer without ulceration, differentiated type, irrespective of tumor size, no lymphovascular invasion

2. Intramucosal cancer with ulceration, differentiated type, $\leq 3 \mathrm{~cm}$ in diameter, no lymphovascular invasion

3. sm1 cancer (minimally invasive submucosal cancer; invasion depth $<500 \mu \mathrm{m}$ from the muscularis mucosa), differentiated type, $<3 \mathrm{~cm}$ in diameter, no lymphovascular invasion, irrespective of ulceration

When the resected lesion was not considered to be an en bloc R0 curative resection [15], further surgical treatment was recommended.

\section{Anticoagulant/antiplatelet agents}

The administration of anticoagulant/antiplatelet drugs was discontinued for at least 1 week before and after ESD. Intravenous heparin (10,000-15,000 U/body/day) was given to those who could not be taken off anticoagulants because of the risk of thrombosis and was stopped $6 \mathrm{~h}$ before and after ESD.

\section{Evaluated parameters}

The clinicopathological data of the ASA 1, ASA 2, and ASA 3 groups were compared with regard to sex, age, frequency and details of anticoagulant/antiplatelet treatment, frequency of steroid use, details of co-morbidities, tumor location, macroscopic type, tumor diameter, resected specimen diameter, histopathological diagnosis, depth of invasion, procedure time, frequency and details of complications related and unrelated to ESD procedure, frequencies of cases treated under the guideline criteria and extended criteria, en bloc $\mathrm{R} 0$ resection rate, curative resection rate, reason for non-curativity, clinical course of non-curatively resected cases, sedative dose used, frequency of hypoxia $\left(\mathrm{SaO}_{2}\right.$, below $\left.90 \%\right)$, and frequency of hypertension and hypotension (change of blood pressure before and after sedation $>40 \%$ ), deviation rate from clinical pathway, and hospital stay. The data examined relative to sedation were limited to cases by experienced anesthesiologists. The impact of a patient's physiological condition on outcome following surgery was objectively assessed using the Portsmouth physiological and operative severity score for enumeration of mortality, and for morbidity we used the other patient risk prediction model on surgery (P-POSSUM) [16, 17].

\section{Statistics}

Values are presented as medians, and the continuous variable and categorical variables were evaluated with the Kruskal-Wallis test. Statview ver. 5.0 and Statcel.2 were used for statistical analysis. $P$ values $\leq 0.05$ were considered to be statistically significant.

\section{Results}

Clinical characteristics of patients

We treated 527 gastric neoplasms from patients with co-morbidities (268 ASA 2 patients and 19 ASA 3 patients) and 240 gastric neoplasms from patients without co-morbidities (240 ASA 1 patients) by ESD according to the typical clinical pathway. Hypertension, diabetes mellitus, and ischemic heart disease were the most common co-morbidities. There were significant differences in age and sex and the use of anticoagulant/antiplatelet agents among the three groups. The median age (in years) of the ASA 2 and ASA 3 groups was higher than that of the ASA 1 group (ASA 1, 68.0; ASA 2, 73.5; ASA 3, 71.0; $P=0.022)$. The percentage of females tended to decrease as the grade of ASA increased (ASA 1, 27.1\%; ASA 2, $19.8 \%$; ASA 3, 15.8\%; $P=0.022$ ). Anticoagulant/antiplatelet agents were taken more often in the co-morbidity groups (ASA 1, 5.8\%; ASA 2, 29.1\%; ASA 3, 31.6\%; $P<0.0001)$, and aspirin was the anticoagulant/antiplatelet agent most commonly used (Table 2).

\section{Clinicopathological characteristics of the tumors}

There were no significant differences among the three groups with regard to tumor location, macroscopic type, tumor diameter, resected specimen diameter, or criteria (Table 3).

\section{Sedation}

Doses of midazolam and flunitrazepam tended to be lower in the co-morbidity groups, although there were no significant differences. The frequency of hypoxia tended to be higher in the ASA 2 group than the ASA 1 group, although none of the cases in the ASA 3 group displayed hypoxia. 
Table 2 Comparison of patient clinical characteristics among the three ASA groups

\begin{tabular}{|c|c|c|c|c|}
\hline & ASA 1 & ASA 2 & ASA 3 & $P$ \\
\hline Patients $(n)$ & 240 & 268 & 19 & \\
\hline Median age (years [range]) & $\begin{array}{l}68.0 \\
{[38.0-92.0]}\end{array}$ & $\begin{array}{l}73.5 \\
{[46.0-91.0]}\end{array}$ & $\begin{array}{l}71.0 \\
\quad[52.0-89.0]\end{array}$ & $<0.0001$ \\
\hline \multicolumn{5}{|l|}{ Sex } \\
\hline Male/female & $175 / 65$ & $215 / 53$ & $16 / 3$ & 0.022 \\
\hline \multicolumn{5}{|l|}{ Comorbidities $(n)$} \\
\hline Hypertension & & 153 & 9 & \\
\hline Diabetes mellitus & & 62 & 9 & \\
\hline Ischemic heart disease & & 55 & 7 & \\
\hline Arrhythmia & & 51 & 1 & \\
\hline Liver dysfunction & & 34 & 4 & \\
\hline Respiratory dysfunction & & 35 & 3 & \\
\hline Renal dysfunction & & 7 & 8 & \\
\hline Cerebral vessel disease & & 24 & 0 & \\
\hline $\begin{array}{l}\text { Anticoagulant/antiplatelet agents [\% }(n)] \\
\text { (single use, } 83 \text { cases; combination use, } 15 \\
\text { cases) }\end{array}$ & $5.8 \%(14 / 240)$ & $\begin{array}{l}29.1 \%(78 / \\
268)\end{array}$ & $31.6 \%(6 / 19)$ & $<0.0001$ \\
\hline Warfarin & 0 & 8 & 0 & \\
\hline Aspirin & 6 & 51 & 4 & \\
\hline Ticlopidine & 2 & 10 & 1 & \\
\hline Clopidogrel sulfate & 0 & 2 & 0 & \\
\hline Ethyl icosapentate & 2 & 2 & 0 & \\
\hline Cilostazol & 0 & 10 & 1 & \\
\hline Limaprost alfadex & 3 & 5 & 0 & \\
\hline Dipyridamole & 0 & 4 & 0 & \\
\hline Sarpogrelate hydrochloride & 0 & 2 & 0 & \\
\hline Ifenprodil tartrate & 1 & 0 & 0 & \\
\hline Steroids $[\%(n)]$ & $0.8 \%(2 / 240)$ & $1.5 \%(4 / 268)$ & $0 \%(0 / 19)$ & 0.703 \\
\hline
\end{tabular}

The frequencies of hypertension and hypotension tended to increase as the grade of ASA increased, but the difference was not statistically significant (Table 4).

\section{Outcome}

There were no significant differences in the procedure time, en bloc R0 resection rate, or curative resection rate among the three groups. The most common reason for non-curativity was massive submucosal invasion. Endoscopic follow-up during the clinical course of the non-curatively resected cases tended to be more frequent in the ASA 2 and ASA 3 groups; however, no recurrence had been observed as of March 2011. There was a significant difference in the frequency of total complications and complications unrelated to ESD procedure among the three groups. The patients in the ASA 2 and ASA 3 groups displayed a higher rate of total complications (ASA 1, 15.4\%; ASA 2, 23.9\%; ASA $3,26.3 \% ; P=0.014)$ and complications unrelated to the ESD procedure (ASA 1, 0.4\%; ASA 2, 7.1\%; ASA 3, $0 \%, P=0.00087)$. The most common complication unrelated to the ESD procedure was delirium, followed by aspiration pneumonia, arrhythmia, and ischemic heart attack caused by sedation. On the other hand, there was no significant difference in complications related to ESD procedure among the groups. The postoperative bleeding rates in the ASA 2 and ASA 3 groups were similar to that in the ASA 1 group. Although there were no significant differences, perforation and thermal injury tended to be more frequent in the higher ASA grades (ASA 1, 2.1\%; ASA 2, 4.1\%; ASA 3, 10.5\%; $P=0.072$, and ASA 1, $8.8 \%$; ASA 2, 10.8\%; ASA 3, 15.8\%; $P=0.30$ ). Deviation from clinical pathway was more frequent (ASA 1, 11.3\%; ASA 2, 17.9\%; ASA 3, 26.3\%; $P=0.014)$, and the hospital stay was longer [ASA 1, 8 days (range, 4-18); ASA 2, 8 days (5-42); ASA 3, 9 days (6-21); $P=0.0053)$ in the higher ASA grades (Table 5).

Based on the multivariate analysis, ASA was significantly associated with total complications [ASA 2 and ASA 3: odds ratio (OR) $1.737,95 \%$ confidence interval (CI) $1.115-2.704, P=0.015$ ), and ASA and age with complications unrelated to ESD procedure (ASA 2 and 
Table 3 Comparison of clinicopathological tumor characteristics among the three ASA groups

\begin{tabular}{|c|c|c|c|c|}
\hline & ASA 1 & ASA 2 & ASA 3 & $P$ \\
\hline Location $[n(\%)]$ & & & & 0.92 \\
\hline Upper & $49(20.4)$ & $60(22.4)$ & $3(15.8)$ & \\
\hline Middle & $92(38.3)$ & $104(38.8)$ & $5(26.3)$ & \\
\hline Lower & $99(41.3)$ & $104(38.8)$ & $11(57.9)$ & \\
\hline \multicolumn{5}{|l|}{ Macroscopic type $(n)$} \\
\hline $0-$ Is & 4 & 13 & 0 & \\
\hline 0-IIa & 86 & 91 & 8 & \\
\hline 0-IIa + IIc & 34 & 26 & 3 & \\
\hline $0-\mathrm{IIb}$ & 4 & 7 & 0 & \\
\hline $0-$ IIc & 110 & 120 & 8 & \\
\hline 0-IIc + IIa & 2 & 11 & 0 & \\
\hline Median tumor diameter (mm [range]) & $18.0[3-112]$ & $18.0[2-132]$ & $21.0[5-50]$ & 0.90 \\
\hline Median resected specimen diameter (mm [range]) & $44.0[14-142]$ & $45.0[18-146]$ & $41.0[26-71]$ & 0.70 \\
\hline \multicolumn{5}{|l|}{ Histopathological diagnosis $(n)$} \\
\hline Adenoma & 3 & 5 & 0 & \\
\hline m-cancer & 190 & 207 & 14 & \\
\hline sm1-cancer & 24 & 29 & 1 & \\
\hline sm2-cancer & 23 & 27 & 4 & \\
\hline Adenoma & 3 & 5 & 0 & \\
\hline tub1 & 160 & 200 & 14 & \\
\hline tub2 & 66 & 53 & 3 & \\
\hline pap & 4 & 7 & 1 & \\
\hline undif & 7 & 3 & 1 & \\
\hline Criteria $[n(\%)]$ & & & & 0.44 \\
\hline Standard guidelines & $101(42.1)$ & $102(38.1)$ & $4(21.0)$ & \\
\hline Expanded & $94(39.2)$ & $115(42.9)$ & $11(58.0))$ & \\
\hline Extra & 45 (18.7) & $51(19.0)$ & $4(21.0)$ & \\
\hline
\end{tabular}

Table 4 Comparison of sedation among the three ASA groups

\begin{tabular}{lllll}
\hline & ASA 1 & ASA 2 & ASA 3 & $P$ \\
\hline Patients $(n)$ & 116 & 139 & 10 & \\
Median dose of drugs/weight $(\mu \mathrm{g} / \mathrm{kg}$ [range]) & & & & \\
$\quad$ Midazolam & $121[18-360]$ & $107[13-450]$ & $96[27-670]$ & 0.21 \\
Flunitrazepam & $18[2.8-69]$ & $16[3.4-40]$ & $11[6.1-13]$ & 0.060 \\
Haloperidol & $41[8-130]$ & $44[10-250]$ & $28[22-34]$ & 0.41 \\
Butorphanol & $22[6.1-64]$ & $20[2.5-91]$ & $22[10-38]$ & 0.37 \\
Hypoxia [\% $(n)]$ & $3.4 \%(4 / 116)$ & $6.5 \%(9 / 139)$ & $0.0 \%(0 / 10)$ & 0.45 \\
Hypertension or hypotension $[\%(n)]$ & $10.3 \%(12 / 116)$ & $17.3 \%(24 / 139)$ & $30.0 \%(3 / 10)$ & 0.0502 \\
\hline
\end{tabular}

ASA 3: OR 13.564, 95\% CI 1.790-102.779, $P=0.012$; age: OR 2.188, 95\% CI 1.172-4.087, $P=0.014)$ (Table 6).

The P-POSSUM showed the predicted surgical risks: morbidity of postoperative bleeding and perforation that require endoscopic treatment and mortality were higher than the observed ESD risks, and there was no incidence of death. The predicted surgical risks were significantly more frequent in the higher ASA grades (predicted morbidity:
ASA 1, 11.5\%; ASA 2, 15.8\%; ASA 3, 33.0\%, $P<0.0001$; and predicted mortality: ASA 1, 0.5\%; ASA 2, 0.7\%; ASA 3, 1.9\%; $P<0.0001$ ) (Table 7).

\section{Discussion}

As a result of increased life expectancy achieved by recent advances in medical treatment, gastroenterologists are 
Table 5 Comparison of outcomes among the three ASA groups

\begin{tabular}{|c|c|c|c|c|}
\hline & ASA 1 & ASA 2 & ASA 3 & $P$ \\
\hline Procedure time (min [range]) & $61[9-369]$ & $59.5[6-288]$ & $54.5[10-119]$ & 0.24 \\
\hline En bloc R0 resection $[\%(n)]$ & $93.8 \%(225 / 240)$ & $92.9 \%(249 / 268)$ & $94.7 \%(18 / 19)$ & 0.76 \\
\hline Curative resection $[\%(n)]$ & $79.6 \%(191 / 240)$ & $79.9 \%(214 / 268)$ & $78.9 \%(15 / 19)$ & 0.71 \\
\hline \multicolumn{5}{|l|}{ Reason for non-curativity $(n)$} \\
\hline sm2-cancer & 20 & 19 & 2 & \\
\hline Tumor size $>30 \mathrm{~mm}$ and sm1-cancer & 9 & 7 & 0 & \\
\hline Tumor size $>30 \mathrm{~mm}$ and ulceration positive & 6 & 11 & 0 & \\
\hline Undifferentiated carcinoma & 6 & 2 & 0 & \\
\hline Vertical margin positive & 2 & 1 & 0 & \\
\hline Lateral margin positive & 1 & 2 & 0 & \\
\hline Lymphatic invasion & 5 & 12 & 2 & \\
\hline Clinical course of non-curatively resected lesions $[n(\%)]$ & & & & 0.064 \\
\hline Endoscopic follow-up & $24(49.0)$ & $38(70.4)$ & $3(75.0)$ & \\
\hline Additional surgical operation & $24(49.0)$ & $15(27.8)$ & $1(25.0)$ & \\
\hline Additional APC, ESD & $1(2.0)$ & $1(1.8)$ & $0(0.0)$ & \\
\hline All complications $[\%(n)]$ & $15.4 \%(37 / 240)$ & $23.9 \%(64 / 258)$ & $26.3 \%(5 / 19)$ & 0.014 \\
\hline Postoperative bleeding & 10 & 7 & & \\
\hline Postoperative bleeding + Thermal injury & & 1 & 1 & \\
\hline Postoperative bleeding + Arrhythmia & & 1 & & \\
\hline Postoperative bleeding + Delirium & & 3 & & \\
\hline Perforation & 5 & 11 & 2 & \\
\hline Thermal injury & 21 & 26 & 2 & \\
\hline Thermal injury + Arrhythmia & & 1 & & \\
\hline Thermal injury + Delirium & & 1 & & \\
\hline Aspiration pneumonia & & 5 & & \\
\hline Arrhythmia & & 2 & & \\
\hline Delirium & 1 & 2 & & \\
\hline Ischemic heart attack & & 4 & & \\
\hline \multicolumn{5}{|l|}{ ESD-related complications $[\%(n)]$} \\
\hline Postoperative bleeding, Perforation, Thermal injury & $15.0 \%(36 / 240)$ & $19.0 \%(51 / 268)$ & $26.3 \%(5 / 19)$ & 0.14 \\
\hline Postoperative bleeding + Perforation $[\%(n)]$ & $6.3 \%(15 / 240)$ & $8.6 \%(23 / 268)$ & $15.8 \%(3 / 19)$ & 0.16 \\
\hline Postoperative bleeding $[\%(n)]$ & $4.2 \%(10 / 240)$ & $4.5 \%(12 / 268)$ & $5.3 \%(1 / 19)$ & 0.82 \\
\hline Perforation $[\%(n)]$ & $2.1 \%(5 / 240)$ & $4.1 \%(11 / 268)$ & $10.5 \%(2 / 19)$ & 0.072 \\
\hline Thermal injury $[\%(n)]$ & $8.8 \%(21 / 240)$ & $10.8 \%(29 / 268)$ & $15.8 \%(3 / 19)$ & 0.30 \\
\hline \multicolumn{5}{|l|}{ ESD-not-related complications $[\%(n)]$} \\
\hline Aspiration pneumonia, Arrhythmia, Delirium, Ischemic heart attack & $0.4 \%(1 / 240)$ & $7.1 \%(19 / 268)$ & $0 \%(0 / 19)$ & 0.00087 \\
\hline Deviation from clinical pathway $[\%(n)]$ & $11.3 \%(27 / 240)$ & $17.9 \%(48 / 268)$ & $26.3 \%(5 / 19)$ & 0.014 \\
\hline Hospital stay (days [range]) & $8[4-18]$ & $8[5-42]$ & $9[6-21]$ & 0.0053 \\
\hline
\end{tabular}

ESD endoscopic submucosal dissection

Thermal injury, thermal injury caused by preventive coagulation

increasingly facing the problem of treating patients with co-morbidities.

Endoscopic mucosal resection (EMR) has become the standard treatment for intramucosal cancer of the gastrointestinal tract because it is less invasive than surgical resection $[18,19]$. The general criteria for EMR for early gastric cancer are limited to the lesions defined in the
Japanese treatment guidelines for early gastric cancer as carrying a negligible risk of lymph node metastasis. However, en bloc resection by EMR is often impossible because the size of the lesions that can be treated by EMR is limited. The ESD technique, which can be performed with a variety of knives, such as the insulated-tip diathermic knife (IT knife) [2, 18], the Hook knife [19], the Flex 
knife [20, 21], and the Flush knife [22-27], allows en bloc resection of intramucosal tumors larger than $20 \mathrm{~mm}$ [2], reduces local recurrence [18, 28], and has been widely accepted [29]. Moreover, a recent study of a large number of surgically resected cases demonstrated that some lesions are candidates for extending the indications for ESD because the risk of lymph node metastasis of the lesion is tolerable [15]. The adoption of the ESD technique is expected to increase the number of patients whose stomachs are spared. The preservation of stomach function is especially important in patients with co-morbidities. Many patients with co-morbidities have come to be treated by ESD; however, ESD has some disadvantages in comparison with EMR, such as increased technical difficulty, longer procedure time, and an increased frequency of complications. Precise preoperative risk assessment is thus important for maximizing the safety of the ESD procedure, especially in patients with co-morbidities. Several articles have evaluated the efficacy and safety of ESD in elderly patients [30-32]; however, patients were only classified according to their age, and no other risk factors were considered. This is the first report to evaluate the safety of ESD in patients with co-morbidities according to their ASA status classification, which has become the most

Table 6 Multivariate analysis of all complications and ESD-notrelated complications among the three ASA groups

\begin{tabular}{lll}
\hline Factors & \multicolumn{2}{c}{ Multivariate analysis } \\
\cline { 2 - 3 } & OR $(95 \% \mathrm{CI})$ & $P$ value \\
\hline All complications & & \\
ASA & 1 (reference) & 0.015 \\
ASA1 & $1.737(1.115-2.704)$ & \\
ASA2, 3 & \\
ESD not-related complications & \\
ASA & 1 (reference) & 0.012 \\
ASA1 & $13.564(1.790-102.779)$ & 0.014 \\
ASA2, 3 & $2.188(1.172-4.087)$ & \\
Age (10 years) &
\end{tabular}

OR odds ratio, $C I$ confidence interval widely used patient perioperative risk assessment scheme in the field of anesthesiology [3-5].

In our ESD results, no significant differences in curativity were observed between the patients with co-morbidities and those without co-morbidities, although the patients with co-morbidities displayed higher rates of anticoagulation therapy. The good ESD results obtained in patients with co-morbidities are considered to result from to the improvement and development of devices and techniques such as the Flush knife, IT knife, high-frequency electrosurgical generator, and improved sedation methods. However, in this study, total complications and complications unrelated to ESD procedure occurred significantly more frequently in patients with co-morbidities.

Thermal injury, which was included in the complications related to the ESD procedure, might have been associated with low hemostatic capability and fragility of the muscle layer. Although preventive coagulation of the visible vessels in the resected area after ESD is reported to lead to a lower postoperative bleeding rate [33], the vessel walls might be more fragile in patients with co-morbid arteriosclerosis [34]; therefore, a delicate coagulation technique separated into several short sessions is required in patients with co-morbidities. Preventive clipping is also considered to be useful in addition to coagulation for those with higher ASA grades for fear of thermal injury.

Complications unrelated to the ESD procedure caused by sedation such as aspiration pneumonia, arrhythmia, ischemic heart attack, and delirium might be associated with weakened respiratory, cardiac, and central nervous function. In our study, we paid close attention to the dose of sedatives administered to patients with co-morbidities. Lower doses of sedatives were sufficient for patients with co-morbidities and were also desirable for the prevention of complications unrelated to the ESD procedure because the functional capabilities of the internal organs of these patients were low. Nevertheless, the rates of hypoxia, hypertension, and hypotension tended to be high. Therefore, precise general control during sedation, especially of respiratory function combined with the monitoring of vital signs, is important for patients with co-morbidities.

Table 7 Observed ESD risk and predicted surgical risks defined by P-POSSUM among the three ASA groups

\begin{tabular}{|c|c|c|c|c|}
\hline & ASA 1 & ASA 2 & ASA 3 & $P$ \\
\hline \multicolumn{5}{|l|}{ Observed ESD risks } \\
\hline Morbidity (postoperative bleeding + perforation) $(\%)$ & 6.3 & 8.6 & 15.8 & 0.25 \\
\hline Mortality (\%) & 0.0 & 0.0 & 0.0 & - \\
\hline \multicolumn{5}{|l|}{ Predicted surgical risks $(\%)$} \\
\hline Predicted morbidity (\%, [range]) & $11.5[6.5-16.7]$ & $15.8[7.6-80.7]$ & $33.0[7.8-79.7]$ & $<0.0001$ \\
\hline Predicted mortality (\%, [range]) & $0.5[0.3-0.7]$ & $0.7[0.3-15.0]$ & $1.9[0.3-15.0]$ & $<0.0001$ \\
\hline
\end{tabular}

$E S D$ endoscopic submucosal dissection 
Multivariate logistic analysis revealed that higher ASA grade was a significant risk factor associated with both total complications and complications unrelated to ESD procedure. Because in this study oral intake was postponed in patients with complications, it might be expected that higher ASA grade was significantly associated with a high rate of deviation rate from the typical clinical pathway and a long hospital stay.

Four cases of postoperative bleeding in the ASA 2 and ASA 3 groups occurred after the patients had been diagnosed with delirium or arrhythmia. Although a causal relationship between postoperative bleeding and delirium or arrhythmia is not definite, we consider that careful observation might be required for higher ASA grade patients with complications unrelated to the ESD procedure.

Although the risks of ESD increased with ASA grade, the predicted risks of surgery were revealed to be still much higher than those of ESD by a patient risk prediction model on surgery, P-POSSUM, which precisely predicts mortality, especially in those at low risk. The higher ASA grade was significantly associated with high predicted morbidity and mortality.

This study had limitations in that it was a retrospective study which had been conducted in a single institution. Moreover, those with comorbidities are eager to remain longer in the hospital, and the doctors may also keep those in the hospital for a longer period, because their quality of life is basically low whereas the national health insurance of Japan will cover more than $70 \%$ of the total cost for the hospital charge. These factors might cause bias toward a longer hospital stay for those with higher ASA grades. Although it is important that the results in this study are analyzed from the point of view of both cost-effectiveness and life expectancy of the patients, we were not able to investigate these aspects because of methodological difficulty.

Therefore, the results might not be applicable to other populations. To confirm the findings reported in this study, a multicenter prospective study involving the typical clinical pathway is required.

\section{Conclusion}

Endoscopic submucosal dissection (ESD) can be performed efficiently for gastric neoplasms in patients with co-morbidities; however, additional caution is required because both total complications and complications unrelated to the ESD procedure were recognized more frequently in patients with co-morbidities than in those without co-morbidities, and the presence of co-morbidities was a significant risk factor for both total complications and complications unrelated to the ESD procedure. These factors may cause both deviation from the clinical pathway and a long hospital stay. This article provides useful information about ESD cases involving co-morbidities.

Conflict of interest Dr. Toyonaga invented the standard Flushknife in conjunction with Fujifilm Inc., Tokyo, Japan, and receives royalties from its sale. He has disclosed to study participants the potential investigator conflict of interest. All other authors have no conflict of interest.

\section{References}

1. Oda I, Gotoda T, Hamanaka H, Eguchi T, Saito Y, Matsuda T, et al. Endoscopic submucosal dissection for early gastric cancer: technical feasibility, operation time and complications from a large consecutive series. Dig Endosc. 2005;17:54-8.

2. Gotoda T, Kondo H, Ono H, Saito Y, Yamaguchi H, Saito D, et al. A new endoscopic mucosal resection procedure using an insulation-tipped electrosurgical knife for rectal flat lesions. Gastrointest Endosc. 1999;50:560-3.

3. Farrow SC, Fowkes FG, Lunn JN, Robertson IB, Samuel P. Epidemiology in anaesthesia. II: factors affecting mortality in hospital. Br J Anaesth. 1982;54:811-7.

4. Pedersen T, Eliasen K, Ravnborg M, Viby-Mogensen J, Qvist J, Johansen SH, et al. Risk factors, complications and outcome in anaesthesia. A pilot study. Eur J Anaesthesiol. 1986;3:225-39.

5. Warner MA, Shields SE, Chute CG. Major and mortality within 1 month of ambulatory surgery and anesthesia. JAMA. 1993;270: 1437.

6. Arbuck SG, Ivy SP, Setser A, et al. The revised common toxicity criteria: version 2.0. CTEP Website. http://ctep.info.nih.gov.

7. Katsinelos P, Kountouras J, Paroutoglou G, Chatzimavroudis G, Zavos C, Pilpilidis I, et al. A comparative study of $50 \%$ dextrose and normal saline solution on their ability to create submucosal fluid cushions for endoscopic resection of sessile rectosigmoid polyps. Gastrointest Endosc. 2008;68:692-8.

8. Ono H, Hasuike N, Inui T, Takizawa K, Ikehara H, Yamaguchi $\mathrm{Y}$, et al. Usefulness of a novel electrosurgical knife, the insulation-tipped diathermic knife-2, for endoscopic submucosal dissection of early gastric cancer. Gastric Cancer. 2008;11:47-52.

9. Toyonaga T, Nishino E, Hirooka T. Invention of water jet short needle knives (Flush knife) for endoscopic submucosal dissection. Endosc Dig 2005;17:2167-74 (in Japanese with English abstract).

10. Toyonaga $\mathrm{T}$, Inokuchi $\mathrm{H}$, Man-i M, Morita $\mathrm{Y}$, Yoshida $\mathrm{M}$, Kutsumi H, et al. Endoscopic submucosal dissection using water jet short needle knives (Flush knife) for the treatment of gastrointestinal epithelial neoplasms. Acta Endosc. 2007;37:645-56.

11. Toyonaga T, Nishino E, Hirooka T, Ueda C, Noda K. Intraoperative bleeding in endoscopic submucosal dissection in the stomach and strategy for prevention and treatment. Dig Endosc. 2006;18:S123-7.

12. Toyonaga T, Nishino E, Dozaiku T, Ueda C, Hirooka T. Management to prevent bleeding during endoscopic submucosal dissection using the Flush knife for gastric tumors. Dig Endosc. 2007;19:S14-8.

13. Introduction to JGCA gastric cancer treatment guidelines. 1st ed. 2001. http://www.jgca.jp/PDFfiles/E-gudeline.PDF.

14. Introduction to JGCA gastric cancer treatment guidelines. 2nd ed. Tokyo: Kanehara; 2004 (in Japanese).

15. Gotoda T, Yanagisawa A, Sasako M, Ono H, Nakanishi Y, Shimoda $\mathrm{T}$, et al. Incidence of lymph node metastasis from early 
gastric cancer: estimation with a large number cases at two large centers. Gastric Cancer. 2000;3:219-25.

16. Copeland GP, Jones D, Walters M. POSSUM: a scoring system for surgical audit. Br J Surg. 1991;78:355-60.

17. Whiteley MS, Prytherch DR, Higgins B, Weaver PC, Prout WG. An evaluation of the POSSUM surgical scoring system. Br J Surg. 1996;83:812-5.

18. Ono H, Kondo H, Gotoda T, Shirao K, Yamaguchi H, Saito D, et al. Endoscopic mucosal resection for treatment of early gastric cancer. Gut. 2001;48:225-9.

19. Oyama T, Kikuchi Y. Aggressive endoscopic mucosal dissection in the upper GI tract: hook knife EMR method. Min Invas Ther Allied Technol. 2002;11:291-5.

20. Yahagi N, Fujishiro M, Kakushima N, Kobayashi K, Hashimoto T, Oka S, et al. Endoscopic submucosal dissection for early gastric cancer using the tip of an electrosurgical snare (thin type). Dig Endosc. 2004;16:34-8.

21. Kodashima S, Fujishiro M, Yahagi N, Kakushima N, Omata M. Endoscopic submucosal dissection using Flex knife. J Clin Gastroenterol. 2006;40:378-84.

22. Toyonaga $T$, Nishino E, Hirooka T, Dozaiku T, Sugiyama T, Sugiyama R, et al. Endoscopic submucosal dissection for the large intestine and selection of treatment apparatus. Endosc Dig. 2004;16:1473-80 (in Japanese with English abstract).

23. Toyonaga T, Nishino E, Hirooka T, Dozaiku T, Sugiyama T, Iwata $\mathrm{Y}$, et al. Use of short needle knife for esophageal endoscopic submucosal dissection. Dig Endosc. 2005;17:246-52.

24. Toyonaga T. ESD atlas. Tokyo: Kanehara; 2006 (in Japanese).

25. Toyonaga T, Man-i M, Ivanov D, Sanuki T, Morita Y, Kutsumi H, et al. The results and limitations of endoscopic submucosal dissection for colorectal tumors. Acta Chir Iugosl. 2008;55:17-23.

26. Toyonaga T, Man-i M, Fujita T, East JE, Nishino E, Ono W, et al. Retrospective study of technical aspects and complications of endoscopic submucosal dissection for laterally spreading tumors of the colorectum. Endoscopy. 2010;42:714-22.

27. Toyonaga T, Man-I M, Fujita T, Nishino E, Ono W, Morita Y, et al. The performance of a novel ball-tipped Flush knife for endoscopic submucosal dissection: a case-control study. Aliment Pharmacol Ther. 2010;32:908-15.

28. Gotoda T. A large endoscopic resection by endoscopic submucosal dissection procedure for early gastric cancer. Clin Gastroenterol Hepatol. 2005;3:S71-3.

29. Rösch T, Sarbia M, Schumacher B, Deinert K, Frimberger E, Toermer $\mathrm{T}$, et al. Attempted endoscopic en bloc resection of mucosal and submucosal tumors using insulated-tip knives: a pilot series. Endoscopy. 2004;36:788-801.

30. Kakushima N, Fujishiro M, Kodashima S, Muraki Y, Tateishi A, Yahagi N, et al. Technical feasibility of endoscopic submucosal dissection for gastric neoplasms in the elderly Japanese population. J Gastroenterol Hepatol. 2007;22:311-4.

31. Shimura T, Joh T, Sasaki M, Kataoka H, Tanida S, Ogasawara N, et al. Endoscopic submucosal dissection is useful and safe for intramucosal gastric neoplasms in the elderly. Acta Gastroenterol Belg. 2007;70:323-30.

32. Hirasaki S, Tanimizu M, Nasu J, Shinji T, Koide N. Treatment of elderly patients with early gastric cancer by endoscopic submucosal dissection using an insulated-tip diathermic knife. Intern Med. 2005;44:1033-8.

33. Takizawa K, Oda I, Gotoda T, Yokoi C, Matsuda T, Saito Y, et al. Routine coagulation of visible vessels may prevent delayed bleeding after endoscopic submucosal dissection: an analysis of risk factors. Endoscopy. 2008;40:179-83.

34. Smith SC Jr, Milani RV, Arnett DK, Crouse JR 3rd, McDermott MM, Ridker PM, et al. Atherosclerotic Vascular Disease Conference: Writing Group II: risk factors. Circulation. 2004;109: 2613-6. 